\title{
ANALISIS SIFAT TERMAL LOGAM URANIUM, PADUAN UMO DAN UMOSi MENGGUNAKAN DIFFERENTIAL THERMAL ANALYZER
}

\author{
YANLINASTUTI, SUTRI INDARYATI, RAHMIATI \\ Pusat Teknologi Bahan Bakar Nuklir-BATAN \\ Serpong
}

\begin{abstract}
Abstrak
ANALISIS SIFAT TERMAL LOGAM URANIUM, PADUAN UMO DAN UMOSI MENGGUNAKAN DIFFERENTIAL THERMAL ANALYZER. Telah dilakukan analisis termal terhadap logam uranium, paduan U-7\%Mo dan U-7\% Mo$1 \%$ Si menggunakan Differential Thermal Analyzer (DTA). Tujuan penelitian ini adalah untuk mengetahui karakterisasi sifat termal diantaranya kestabilan panas, temperatur reaksi termokimia dan entalpi. Dari hasil analisis menunjukkan bahwa logam uranium mengalami perubahan fasa $\alpha$ menjadi fasa $\beta$ pada temperatur $667,16^{\circ} \mathrm{C}$ dengan entalpi sebesar $2,3034 \mathrm{cal} / \mathrm{g}$ dan pada temperatur $773,05^{\circ} \mathrm{C}$ mengalami perubahan fasa $\beta$ menjadi fasa $\gamma$ dengan panas yang dibutuhkan sebesar $2,8725 \mathrm{cal} / \mathrm{g}$ serta pada temperatur $1125,26{ }^{\circ} \mathrm{C}$ logam uranium tersebut mengalami peleburan menjadi cair dengan panas yang dibutuhkan sebesar 2,1316 cal/g. Sedangkan paduan U-7\% Mo mempunyai kestabilan panas hingga temperatur $650^{\circ} \mathrm{C}$, namun diatas temperatur $673,75^{\circ} \mathrm{C}$, paduan U-7\% Mo mengalami perubahan aliran panas yang ditunjukkan oleh reaksi termokimia dengan terbentuknya puncak endotermik dengan membutuhkan panas sebesar $0.0257 \mathrm{cal} / \mathrm{g}$. Paduan U-7\%Mo$1 \%$ Si mempunyai kestabilan panas hingga $550^{\circ} \mathrm{C}$, namun pada temperatur $574,18^{\circ} \mathrm{C}$ paduan tersebut mengalami reaksi termokimia dengan terbentuknya puncak endotermik dengan membutuhkan panas sebesar $0,613 \mathrm{cal} / \mathrm{g}$. Dari ke tiga reaksi termokimia dapat diketahui bahwa logam uranium, paduan U-7\% Mo dan U-7\% Mo$1 \% \mathrm{Si}$ mempunyai kestabilan panas relatif baik hingga temperatur $550^{\circ} \mathrm{C}$.
\end{abstract}

Kata kunci : Termal, UMo, UMoSi, DTA dan reaktor riset

\begin{abstract}
THERMAL ANALYSIS OF PURE URANIUM METAL, UMO AND UMOSI ALLOYS USING A DIFFERENTIAL THERMAL ANALYZER. Thermal analysis of pure uranium metal, U-7\% Mo and U-7\%Mo- $1 \% \mathrm{Si}$ alloys have been done using a Differential Thermal Analyzer (DTA). The experiments are conducted in order to measure the thermal stability, thermochemical properties of elevated temperature and enthalpy of the specimens. From the analysis results it is showed that uranium metal will transform from $\alpha$ to $\beta$ phases at temperature of $667.16^{\circ} \mathrm{C}$ and enthalpy of $2.3034 \mathrm{cal} / \mathrm{g}$ and from $\beta$ to $\gamma$ phases at temperature of $773.05{ }^{\circ} \mathrm{C}$ and enthalpy of $2.8725 \mathrm{cal} / \mathrm{g}$ and start melting at temperature of $1125.26{ }^{\circ} \mathrm{C}$ and enthalpy of $2.1316 \mathrm{cal} / \mathrm{g}$. The U-7\% Mo shows its thermal stability up to temperature of $650^{\circ} \mathrm{C}$ and its thermal changes at temperature of $673.75^{\circ} \mathrm{C}$ indicated by the formation of an
\end{abstract}


endothermic peak and enthalpy of $0.0257 \mathrm{cal} / \mathrm{g}$. The U-7\%Mo- $1 \% \mathrm{Si}$ alloys shows its thermal stability up to temperature of $550 \mathrm{oC}$ and its thermal changes at temperature of $574.18^{\circ} \mathrm{C}$ indicated by the formation of an endothermic peak and enthalpy of $0.613 \mathrm{cal} / \mathrm{g}$. From the three specimens it is swowed that they have agood thermal stability at temperature up to $550^{\circ} \mathrm{C}$.

Keywords: Thermal, UMo, UMoSi, DTA and research reactors

\section{PENDAHULUAN}

Bahan bakar dispersi tipe pelat telah dikenal dan digunakan sebagai bahan bakar reaktor riset sejak tahun 1950 an. Pada waktu itu bahan bakar yang digunakan adalah bahan bakar $\mathrm{UAl}_{\mathrm{x}}-\mathrm{Al}$ dengan pengayaan uranium tinggi $\left(\mathrm{U}^{235}>90 \%\right)$ yang di dispersikan ke dalam matriks Al. Penggunaan uranium pengayaan tinggi dikhawatirkan disalah gunakan oleh orang-orang yang tidak bertanggung jawab, maka sejak tahun 1978 dicanangkan pengalihan penggunaan uranium dari pengayaan tinggi ke pengayaan rendah yang dimotori oleh USA. Dampak dari penggunakan uranium rendah terjadi penurunan jumlah $\mathrm{U}^{235}$ pada volume bahan bakar tetap. Untuk mempertahankan jumlah $\mathrm{U}^{235}$ agar sama dengan menggunakan uranium pengayaan tinggi, maka perlu dipilih material bahan bakar baru yang mempunyai berat jenis tinggi sehingga dapat dicapai densitas uranium antara $8 \mathrm{~s} / \mathrm{d} 9 \mathrm{gU} / \mathrm{cm}^{3[1]}$.

Uranium pengayaan rendah telah digunakan dalam bahan bakar dispersi $\mathrm{UAl}_{\mathrm{x}}-\mathrm{Al}, \mathrm{U}_{3} \mathrm{O}_{8}-\mathrm{Al}$ dan $\mathrm{U}_{3} \mathrm{Si}_{2}-\mathrm{Al}$ dengan unjuk kerja selama digunakan di dalam reaktor cukup baik, namun densitas uranium maksimum yang dapat dicapai masing-masing adalah 2,7, 3,2 dan 4,8 gU/ $\mathrm{cm}^{3}$. Densitas uranium tersebut masih jauh dari yang diharapkan yaitu antara $8 \mathrm{~s} / 9 \mathrm{gU} / \mathrm{cm}^{3[2]}$. Oleh karena itu penelitian material baru untuk memenuhi densitas uranium tersebut terus dilakukan oleh para periset di dunia. Sebagai alternatif, material yang dikembangkan sampai saat ini antara lain adalah paduan uranium berbasis UMo. Paduan UMo dipilih sebagai bahan bakar baru untuk reaktor riset dalam rangka pengembangan bahan bakar $\mathrm{UAl}_{\mathrm{x}}-\mathrm{Al}, \mathrm{U}_{3} \mathrm{O}_{8}-\mathrm{Al}$ dan $\mathrm{U}_{3} \mathrm{Si}_{2}-\mathrm{Al}$ yang telah digunakan sebagai bahan bakar hingga saat ini ${ }^{[2,3]}$.

Paduan UMo mempunyai densitas sekitar $16,4 \mathrm{~g} / \mathrm{cm}^{3}$ (tergantung kadar Mo), lebih tinggi dibanding $\mathrm{U}_{3} \mathrm{Si}_{2}$ yang hanya sekitar $12,2 \mathrm{~g} / \mathrm{cm}^{3}$. Menggunakan paduan UMo sebagai bahan bakar dispersi dapat ditingkatkan hingga densitas uranium dalam meat bahan bakar $9 \mathrm{~g} \mathrm{U} / \mathrm{cm}^{3}$. Keunggulan lain yang dimiliki paduan UMo diantaranya adalah daerah fasa gamma $(\gamma)$ relatif besar, mempunyai stabilitas mikrostruktur pada fasa $\gamma$ relatif baik dan kompabilitas termal dengan matrik $\mathrm{Al}$ relatif baik ${ }^{[4]}$. Penambahan unsur Si ke dalam bahan bakar UMo merupakan kandidat penstabil terjadinya interaksi 
layer. Perlakuan panas paduan $\gamma \mathrm{U}-7 \% \mathrm{Mo}-1 \%$ Si adalah fasa $\gamma \mathrm{U}$ yang metastabil, dan pada konsentrasi Mo dan Si tinggi membentuk endapan (UMo) ${ }_{2} \mathrm{Si}$ di batas butir. Butiran dan densitas endapan menjadi lebih keras seiring kenaikan kadar $\mathrm{Si}^{[5]}$. Tujuan dari penelitian ini digunakan untuk mengetahui sifat-sifat termal, agar dapat menjadi masukan kepada pembuat bahan bakar reaktor riset untuk mendesain bahan bakar jenis molibdenum. Sedangkan sifat-sifat termal paduan UMo dan UMoSi yang akan dianalisi berkaitan dengan kestabilan panas, entalpi dan temperatur reaksi termokimia. Hipotesis yang dapat disampaikan adalah bahwa penambahan Si yang ada dalam paduan akan mempengaruhi karakteristik sifat termal.

Lingkup penelitian ini dibatasi hanya pada karakterisasi sifat termal dari logam uranium, paduan U-7\%Mo dan U-7\%Mo-1\%Si hasil peleburan. Dalam penelitian ini, karakterisasi termal terhadap logam uranium, paduan U-7\% Mo dan U-7\%Mo- $1 \%$ Si dilakukan pada temperatur antara $30-1000^{\circ} \mathrm{C}$ dengan laju pemanasan $10{ }^{\circ} \mathrm{C} /$ menit. Sifat termal yang akan dianalisis pada penelitian ini adalah pengaruh Si terhadap paduan U-7\%Mo dan U-7\%Mo$1 \% \mathrm{Si}$ yang meliputi kestabilan panas, entalpi dan temperatur reaksi termokimia. Pengukuran termal dilakukan dengan menggunakan alat Differential Thermal Analyzer (DTA). Prinsip dasar analisis termal adalah pengaruh panas terhadap perubahan fisik dari bahan yang diukur sebagai fungsi temperatur dan waktu. Hasil analisis DTA berupa termogram puncak endotermik atau eksotermik berupa aliran panas dievaluasi dengan temperatur mulai terbentuknya puncak tersebut disebut onset temperatur dan titik akhir terbentuknya puncak tersebut disebut top temperatur yang menunjukkan besarnya temperatur reaksi, sedangkan luas puncak yang terbentuk menunjukkan entalpi yang dibutuhkan atau dilepaskan oleh bahan ${ }^{[6]}$. Sifat termal paduan dapat digunakan sebagai bahan pertimbangan dalam penggunaan bahan bakar reaktor riset.

\section{TATA KERJA}

\section{Bahan}

Logam uranium, paduan/ingot U-7\%Mo dan U-7\%Mo-1\%Si hasil peleburan dan gas argon UHP 99,99\%

\section{Peralatan}

Timbangan analitik, krusibel alumina dan seperangkat alat Differential Thermal Anaylzer (DTA) merk SETARAM 92 


\section{Cara Kerja}

Logam uranium, paduan/ingot U-7\%Mo dan U-7\%Mo-1\%Si hasil peleburan disiapkan. Logam uranium ditimbang seberat $100 \mathrm{mg}$ kemudian dimasukkan kedalam krusibel alumina, selanjutnya dimasukkan kedalam chamber DTA rod kemudian divakum hingga tekanan $10^{-1}$ bar. Setelah kondisi vakum tercapai, chamber DTA rod dialiri gas argon hingga tekanan 2,5 bar. Analisis termal logam uranium dilakukan dari temperatur $30^{\circ} \mathrm{C}$ hingga $1000^{\circ} \mathrm{C}$ dengan kecepatan pemanasan $10^{\circ} \mathrm{C} /$ menit. Hasil analisis DTA berupa termogram puncak endotermik atau eksotermik berupa aliran panas dievaluasi. Pengukuran sifat termal paduan U-7\%Mo U-7\%Mo-1\%Si dilakukan dengan cara yang sama seperti pada pengukuran logam uranium.

\section{HASIL DAN PEMBAHASAN}

Pada penelitian ini telah dilakukan karakterisasi termal logam uranium, paduan U-7\%Mo dan U-7\%Mo-1\%Si. Hasil analisis dari ketiga paduan tersebut ditunjukkan pada Gambar 1-3. Dari Gambar 1 dan Tabel 1 terlihat bahwa logam uranium mengalami perubahan fasa sebanyak tiga tahap yaitu pada temperatur $667,16^{\circ} \mathrm{C}, 773,05^{\circ} \mathrm{C}$ dan $1125,26^{\circ} \mathrm{C}$. Perubahan fasa pada temperatur diatas menunjukkan terjadi perubahan fasa $\alpha$ menjadi fasa $\beta$ pada temperatur $667,16^{\circ} \mathrm{C}$ dengan panas yang dibutuhkan sebesar $2,3034 \mathrm{cal} / \mathrm{g}$ dan pada temperatur $773,05^{\circ} \mathrm{C}$ mengalami perubahan fasa $\beta$ menjadi fasa $\gamma$ dengan panas yang dibutuhkan sebesar $2,8725 \mathrm{cal} / \mathrm{g}$ serta pada temperatur $1125,26^{\circ} \mathrm{C}$ logam uranium tersebut mengalami peleburan menjadi cair dengan panas yang dibutuhkan sebesar 2,1316 cal/g.

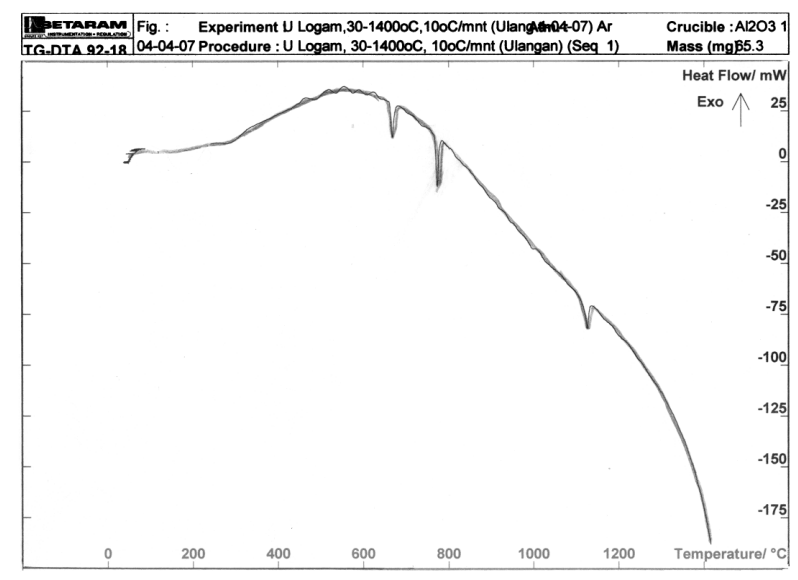

Gambar 1. Termogram DTA Logam Uranium 
Sedangkan dari analisis sifat termal paduan U-7\%Mo diperoleh hasil kestabilan panas hingga temperatur $650^{\circ} \mathrm{C}$, namun pada temperatur $673,75^{\circ} \mathrm{C}$ terjadi rekasi termokimia dengan terbentuknya puncak endotermik dengan membutuhkan panas sebesar $0.0257 \mathrm{cal} / \mathrm{g}$ seperti terlihat pada Gambar 2 dan Tabel 1.

Hal ini menunjukkan bahwa penambahan unsur Mo mempengaruhi aliran panas logam uranium dari temperatur $667,16^{\circ} \mathrm{C}$ menjadi $673,75^{\circ} \mathrm{C}$. Hasil analisis termal terhadap paduan U-7\% Mo- $1 \% \mathrm{Si}$ diperoleh bahwa dengan penambahan unsur $\mathrm{Si}$ terhadap paduan U-7\% Mo menyebabkan penurunan kestabilan panas dari temperatur $673,75^{\circ} \mathrm{C}$ menjadi $574,18^{\circ} \mathrm{C}$ seperti terlihat pada Gambar 3 dan Tabel 1. Pada temperatrur $673,75^{\circ} \mathrm{C}$ paduan U-7\%Mo-1\%Si mengalami reaksi termokimia dengan membutuhkan panas sebesar $0,613 \mathrm{cal} / \mathrm{g}$.

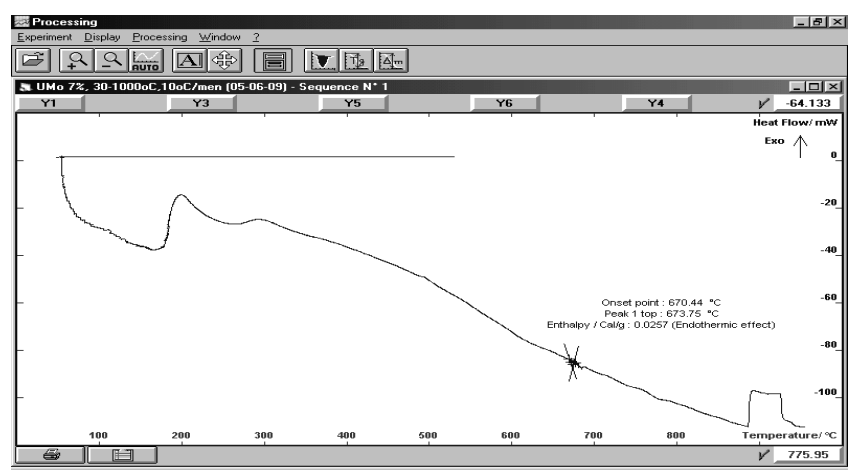

Gambar 2. Termogram DTA Paduan U-7\%Mo

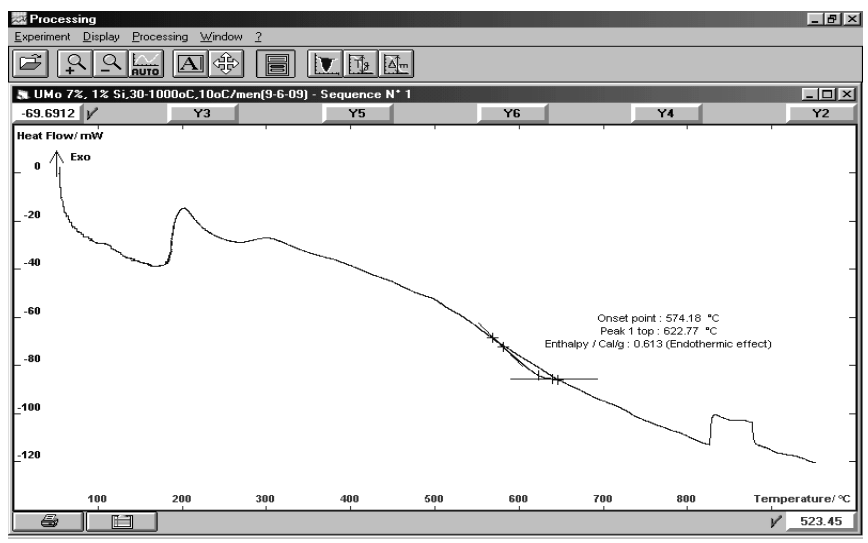

Gambar 3. Termogram DTA Paduan U-7\%Mo-1\% Si 
Tabel 1. Temperatur Reaksi Termokimia dan Entalpi Logam Uranium, Paduan U-7\%Mo dan U-7\%Mo-1\%Si

\begin{tabular}{|c|c|c|c|}
\hline \multirow[b]{2}{*}{ Sampel } & \multicolumn{3}{|c|}{ Perubahan fasa yang terjadi } \\
\hline & $\begin{array}{c}\text { Temp. } \\
\left({ }^{\circ} \mathrm{C}\right)\end{array}$ & $\begin{array}{c}\text { Entalpi } \\
(\mathrm{cal} / \mathrm{g})\end{array}$ & Fenomena \\
\hline Logam U & $\begin{array}{c}667,16 \\
773,05 \\
1125,2 \\
6\end{array}$ & $\begin{array}{l}2,3034 \\
2,8725 \\
2,1316\end{array}$ & $\begin{array}{l}\text { Perubahan fasa } \alpha \text { menjadi fasa } \beta \\
\text { Perubahan fasa } \beta \text { menjadi fasa } \gamma \\
\text { Mengalami peleburan menjadi cair }\end{array}$ \\
\hline $\mathrm{U}-7 \% \mathrm{Mo}$ & 673,75 & 0,0257 & Perubahan fasa $\alpha$ menjadi fasa $\beta$ \\
\hline $\mathrm{U}-7 \% \mathrm{Mo}-1 \% \mathrm{Si}$ & 574,18 & 0,613 & Reaksi termokimia terjadi pada fasa $\alpha+\gamma$ \\
\hline
\end{tabular}

\section{KESIMPULAN}

Hasil analisis sifat termal logam uranium, paduan U-7\%Mo dan U-7\%Mo$1 \% \mathrm{Si}$ menggunakan DTA dapat disimpulkan bahwa logam uranium mengalami reaksi termokimia sebanyak 3 (tiga) tahap pada temperatur $667,16^{\circ} \mathrm{C} ; 773,05^{\circ} \mathrm{C}$ dan $1125,26^{\circ} \mathrm{C}$ dengan masing-masing entalpi sebesar 2,3034 cal/g, 2,8725 cal/g dan 2,1316 cal/g. Paduan U-7\%Mo mengalami reaksi termokimia pada temperatur $673,75^{\circ} \mathrm{C}$ dengan membutuhkan panas sebesar $0.0257 \mathrm{cal} / \mathrm{g}$, sedangkan $\mathrm{U}-7 \% \mathrm{Mo}-1 \% \mathrm{Si}$ mengalami reaksi termokimia pada temperatur $574,18^{\circ} \mathrm{C}$ dengan membutuhkan panas sebesar $0,613 \mathrm{cal} / \mathrm{g}$. Dari ke tiga reaksi termokimia dapat diketahui bahwa logam uranium, paduan U-7\% Mo dan U-7\% Mo- $1 \% \mathrm{Si}$ hingga temperatur $550^{\circ} \mathrm{C}$ mempunyai kestabilan panas cukup baik.

\section{SARAN}

Untuk mengetahui sifat termal lainnya dan untuk melengkapi data dari bahan bakar UMo maka perlu dilakukan penelitian lebih lanjut.

\section{UCAPAN TERIMA KASIH}

Penulis mengucapkan terima kasih kepada Bapak Ir. Supardjo, MT dan Ibu Ir. Aslina Br. Ginting yang telah membantu dan memberikan saran sehingga selesainya makalah ini.

\section{DAFTAR PUSTAKA}

1. VACELET, H,et.al, 1999, "Irradiation of Fuel Umo Plate", 22nd RERTR, Budapest, October 3-8 
2. GINTING BR ASLINA, 2005, "Kompatibilitas Matrik Al Dengan Bahan Bakar Jenia UMo", Hasil-hasil Penelitian EBN Tahun 2005, ISSN 0854 - 5561

3. BUDI BRIYATMOKO, 2005, "Kajian Sintesa Paduan U-Mo Dengan Cara Peleburan”, Hasil Hasil Penelitian EBN Tahun 2005, ISSN 0854 - 5561.

4. AL HASA M. HUSNA, 1998, "Prospek Bahan Bakar Maju U-Mo Berdensitas Tinggi Sebagai Bahan Bakar Reaktor Riset", Prosiding Presentasi Ilmiah Daur Bahan Bakar Nuklir IV PEBN-BATAN, Jakarta.

5. KIM, Y.S, HOFFMAN, G.L, RYU, H.J, FINLAY, M.R Wachs, D, 2006, "Interaction Layer Growth Correlations for (U-Mo)/Al and Si-added (UMo)/Al Dispersion Fuel”, Proc. 2006 RERTR, Intern. Meeting, Cape Town, South Africa.

6. SETARAM, 1992, Manual Operation Alat TGDTA/DSC, France. 
